\title{
Etiology of newly-diagnosed cases of chronic liver disease in Southern Italy: results of a prospective multicentric study
}

\author{
Antonio Ascione, ${ }^{1,2}$ Mario Masarone,,${ }^{2,3}$ Giovanni Tritto, ${ }^{1}$ Carmine Coppola,${ }^{4}$ Cristina Mascolo, ${ }^{4}$ Marcello Persico, ${ }^{3}$ \\ Giovanbattista Forte, ${ }^{5}$ Luca Fontanella, ${ }^{2}$ Massimo De Luca, ${ }^{1}$ Giovan Giuseppe Di Costanzo, ${ }^{1}$ the SCIROCCO \\ Study Group
}

${ }^{1}$ UO Epatologia, Dipartimento di Gastroenterologia, AORN A. Cardarelli, Napoli; ${ }^{2}$ Dipartimento di Medicina Interna, Centro per le malattie del fegato, Ospedale Fatebenefratelli, Napoli; ${ }^{3}$ IV Divisione di Medicina Generale ed Epatologia, Seconda Università di Napoli; ${ }^{4}$ Centro di Epatologia, Divisione di Medicina Generale, Ospedale S. Leonardo, Castellammare di Stabia (NA); ${ }^{5}$ Gastroenterologia ed Endoscopia Digestiva, AO San Sebastiano, Caserta, Italy

\begin{abstract}
The pattern of liver diseases has radically changed in our country over the last few decades. We prospectively collected data on the newly-diagnosed cases of chronic liver diseases in a region of southern Italy after about a decade from the last epidemiological study. We conducted a multicentric prospective study that enrolled 631 patients from 21 Liver Centers of the Campania region (Southern Italy) at their first hospital admission or at their first outpatient visit. In our cohort of 631 patients (367 males, 263 females), 397 (62.9\%) were hepatitis C virus (HCV) positive, 75 (11.9\%) were hepatitis B virus (HBV) positive, $8(1.3 \%)$ were co-infected by HBV and HCV, 73 (11.6\%) had an alcoholic liver disease and $64(10.1 \%)$ had a nonalcoholic fatty liver disease. HBV infection was present in young people with a higher-than-expected prevalence, despite the vaccination program which should have involved this population. HCV chronic hepatitis still remains the most common cause of liver disease in our region. HBV infection still continues to represent a health problem in young people, despite the vaccination program.
\end{abstract}

\section{Introduction}

The incidence of liver diseases in Italy has been investigated several times in the last few years. On the basis of this data Italy has been indicated as a hyper-endemic region in which both viral and meta-

Correspondence: Antonio Ascione, Dipartimento di Medicina Interna, Centro per le malattie del fegato, Ospedale Fatebenefratelli, via Alessandro Manzoni 220, 80126 Napoli, Italy.

Tel.: +39.081.5981877.

E-mail: ascioa@tin.it

Key words: hepatitis B virus infection, chronic liver disease, hepatitis $\mathrm{C}$ virus infection.

Conflict of interests: the authors declare no potential conflict of interests.

Contributions: the authors contributed equally.

Received for publication: 19 July 2013.

Revision received: 19 September 2013.

Accepted for publication: 23 September 2013.

This work is licensed under a Creative Commons Attribution NonCommercial 3.0 License (CC BY-NC 3.0).

CCopyright A. Ascione et al., 2014

Licensee PAGEPress, Italy

Italian Journal of Medicine 2014; 8:176-181

doi:10.4081/itjm.2013.409 bolic etiologies are responsible for a high prevalence and incidence of chronic liver diseases. ${ }^{1-5}$ Moreover, the incidence of viral hepatitis increases progressively from Northern to Southern Italy. ${ }^{4-7}$ Nevertheless, the same studies have also indicated that the etiology of liver disease has changed considerably in recent years. As to hepatitis B virus (HBV), the vaccination program along with improvement in socioeconomic conditions and a greater awareness of the population on how to avoid infection progressively reduced the incidence and the prevalence of this viral disease from the 1970s to the late 1990s. ${ }^{8,9}$ Hepatitis $\mathrm{C}$ virus (HCV)-related chronic hepatitis, after an increase in the 1980s and the 1990s that made this etiology the most prevalent cause of chronic viral hepatitis in Italy, ${ }^{1,10-14}$ has slightly decreased, particularly among young people. ${ }^{15}$ On the other end, other studies have investigated the emerging issue of nonalcoholic fatty liver disease (NAFLD), which is indicated as one of the most common causes of liver disease worldwide ${ }^{16,17}$ and in Italy. ${ }^{18}$ Lastly, alcoholic liver disease is still an open issue, especially in young people, who have shown an increase in incidence and prevalence. ${ }^{19,20}$ However, the most recent epidemiological data regarding the Italian population was collected in the late 1990s. Since a decade has now elapsed, it was thought it might be of interest to collect new data on the pattern of the prevalence of liver diseases in Southern Italy. 


\section{Materials and Methods}

The study was conducted by the SCIROCCO Study Group for Liver Disease, consisting of 21 centers involved in either liver disease or internal medicine or infectious disease, located in the Campania region (Southern Italy). Data was prospectively recorded via a website over a period of 6 months. Only patients at their first hospital admission or at their first outpatient visit were considered, if they were never seen before in any hospital for liver problems. Data was recorded anonymously and cases were identified only by an alphanumeric code. Each center had a direct access to a web site (http: \sscirocco.ospedalecardarelli.it), where it could enter its own data. Each center could access and modify only its own data. Diagnosis was based on clinical, biochemical, and imaging data, and histology, if required. Chronic hepatitis was defined as a history of elevated aminotransferase for at least 6 months. Diagnosis of cirrhosis, when not morphologically established, was based on 2 or more of the following items: thrombocytopenia (less than $100 \mathrm{~mm}^{3}$ ), esophageal varices, ascites, typical ultrasonographic signs (irregular surface, enlargement of portal vein and spleen, portal collaterals). Alcohol consumption was evaluated in terms of type of alcoholic beverage, number of daily drinks and duration of alcohol habit. Every drink (250 $\mathrm{mL}$ for beer, $120 \mathrm{~mL}$ for wine and $40 \mathrm{~mL}$ for spirits) was presumed to be equivalent to $12.5 \mathrm{~g}$ of alcohol. A patient was considered as having alcohol-related liver disease, if he/she had an alcohol intake equal to/more than 3 daily drinks ( $37.5 \mathrm{~g}$ ) for males or equal to/more than 2 daily drinks ( $25 \mathrm{~g}$ ) for females, in the absence of $\mathrm{HCV} / \mathrm{HBV}$ infection and any other cause of liver damage. Any amount of alcohol intake was considered a significant co-factor in patients carrying $\mathrm{HBV}$ and/or
$\mathrm{HCV}$ infection. Markers of infection were assessed by the latest standardized methods: hepatitis B surface antigen (HBsAg) [commercial microparticle enzyme immunoassay (MEIA)], HBV-DNA [real time polymerase chain reaction (PCR)], HCV-antibodies [enzyme-linked immunosorbent assay (ELISA III)] and HCV-RNA (real time PCR) tests. The diagnosis of NAFLD and non-alcoholic steato-hepatitis (NASH) was defined on the basis of the presence of a bright liver echo pattern on abdominal ultrasound $\mathrm{d}^{21,22}$ and/or steatosis in liver biopsy together with the exclusion of any other cause of liver disease, including autoimmunity and alcohol intake. Demographic data and continuous variables were expressed as medians and ranges. Statistical analysis was performed by the SPSS software (Statistical Package for Social Sciences ${ }^{\circledR}$, version 11.0 for Windows ${ }^{\circledR}$; IBM Corp., Armonk, NY, USA). Differences between quantitative variables were evaluated by the Mann-Whitney test. Statistical significance of contingency tables was evaluated by the chi-square test. Differences were considered significant, when $\mathrm{P}<0.05$.

\section{Results}

Six hundred and thirty one consecutive new cases of chronic liver disease (367 males, 264 females), median age 50 years (range: 19-84) were recorded (Table 1). Seventy five patients were HBsAg positive $(11.9 \%)$, 397 were anti-HCV positive $(62.9 \%), 8(1.3 \%)$ had both HBV and HCV infection, 73 patients had an alcoholic liver disease $(11.5 \%), 64(10.1 \%)$ had a NAFLD/NASH and $14(2.2 \%)$ had other causes of liver disease (primary biliary cirrhosis: $3(0.5 \%)$, hemochromatosis $2(0.3 \%)$, Wilson's disease $1(0.15 \%)$, celiac disease $4(0.6 \%)$, drug-related hepatitis 4 (0.6\%). Distribution of HCV genotypes was: genotype

Table 1. General features of patients.

\begin{tabular}{lcccc}
\hline & Overall & Males & Females & P \\
\hline Number & 631 & 367 & 264 & - \\
\hline Age median (range) & $50(19-84)$ & - & - & - \\
\hline Gender (M/F) & $367 / 264$ & - & - & \\
\hline Etiology & & & \\
HBV & $75(11.9 \%)$ & $47(12.8 \%)$ & $28(10.6 \%)$ & $\mathrm{ns}$ \\
HCV & $397(62.9 \%)$ & $215(58.6 \%)$ & $182(45.8 \%)$ & $>0.01$ \\
HBV+HCV & $8(1.3 \%)$ & $6(1.6 \%)$ & $2(0.7 \%)$ & $\mathrm{ns}$ \\
Alcohol without HBV or HCV & $73(11.6 \%)$ & $51(13.9 \%)$ & $22(8.3 \%)$ & $>0.05$ \\
NAFLD/NASH & $64(10.1 \%)$ & $42(11.4 \%)$ & $22(8.3 \%)$ & $\mathrm{ns}$ \\
Primary biliary cirrhosis & $3(0.5 \%)$ & $0(0 \%)$ & $3(1.1 \%)$ & $\mathrm{ns}$ \\
Hemochromatosis & $2(0.3 \%)$ & $2(0.5 \%)$ & $0(0 \%)$ & $\mathrm{ns}$ \\
Wilson's disease & $1(0.15 \%)$ & $1(0.27 \%)$ & $0(0 \%)$ & $\mathrm{ns}$ \\
Celiac disease & $4(0.6 \%)$ & $1(0.27 \%)$ & $3(1.1 \%)$ & $\mathrm{ns}$ \\
Drug-related hepatitis & $4(0.6 \%)$ & $2(0.54 \%)$ & $2(0.75 \%)$ & $\mathrm{ns}$
\end{tabular}

HBV, hepatitis B virus; ns, not significant; HCV, hepatitis C virus; NAFLD, non-alcoholic fatty liver disease; NASH, non-alcoholic steato-hepatitis. No statistically significant difference was found in etiology distribution between males and female except for HCV and alcohol etiologies. 
1: $64 \%$; genotype 2: $25 \%$; genotype $3: 10 \%$; genotype 4: less than $1 \%$.

Causes for referral were: chronic hepatitis with abnormal alanine aminotransferase (ALT) in 74.64\%, serum viral markers positivity with normal ALT in $13.9 \%$, compensated cirrhosis $(8.08 \%)$, decompensated cirrhosis $(2.54 \%)$ and hepatocellular carcinoma $(1.74 \%)$. The etiology distribution of these clinical conditions is reported in Figure 1.

Figure 2 shows age distribution of patients according to the etiology. As expected HCV prevalence was high in the 50-59 and the 60-69 age groups. Neverthe- less, the prevalence in the 20-29 age group was higher than expected, despite the indications from previous studies that highlighted a reduction in $\mathrm{HCV}$ incidence in young people. More surprisingly, 8 out of the 75 (10.7\%) newly diagnosed cases of HBsAg positive hepatitis were in the 20-29 age group, including patients that should have been vaccinated (the HBV vaccination program started in 1991 for neonates and for 12 years olds). The prevalence pattern of incident cases of HBV hepatitis shows a flat distribution with an almost constant percentage of new cases in all age groups from 30-39 to 50-59 years of age, with a de-

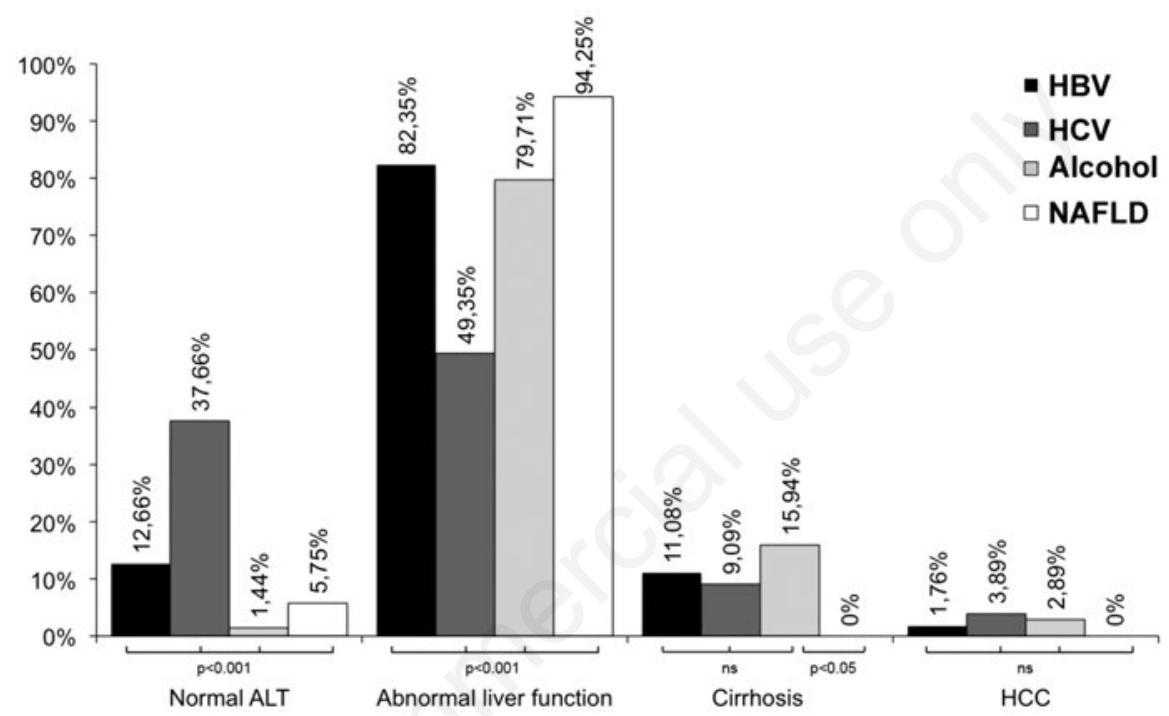

Figure 1. Reasons for referring to liver center. HBV, hepatitis B virus; HCV, hepatitis C virus; NAFLD, non-alcoholic fatty liver disease; ALT, alanine aminotransferase; HCC, hepatocellular carcinoma.

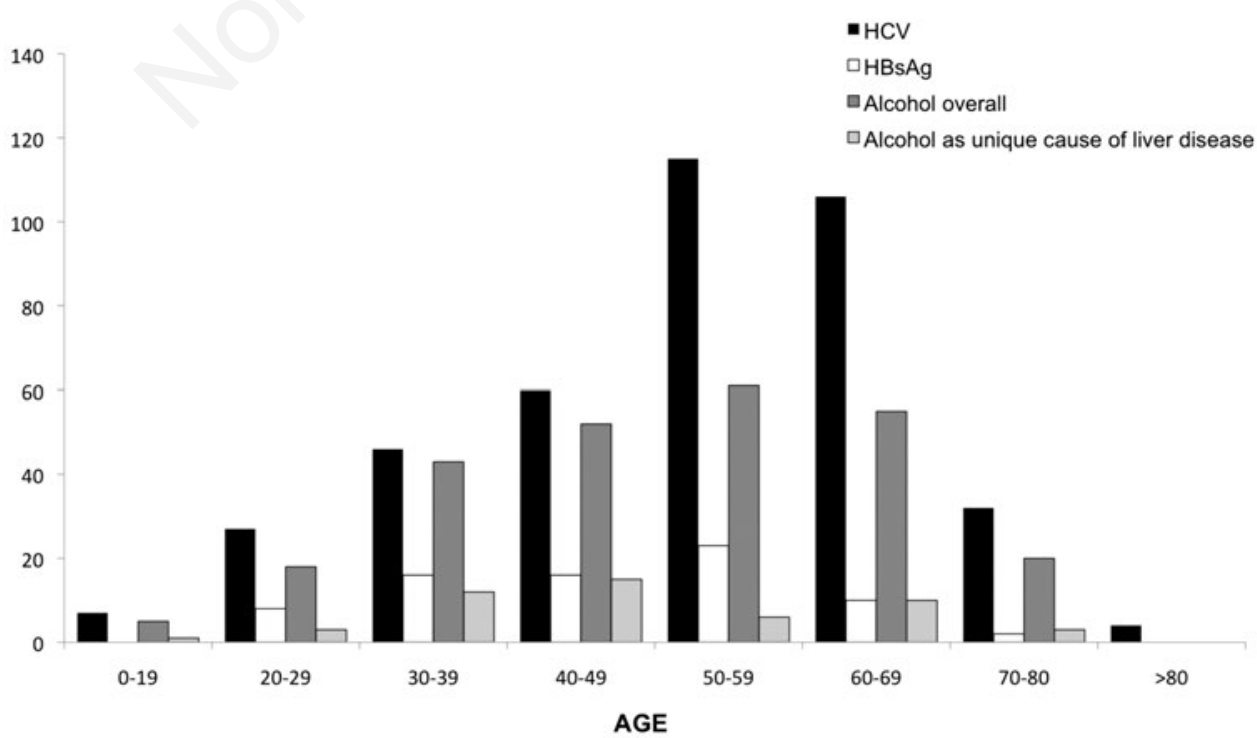

Figure 2. Age distribution by liver etiology. HCV, hepatitis C virus; HBsAg, hepatitis B surface antigen. 
crease in 60-69 and 70-80 age groups. A similar pattern was found in alcohol-related chronic hepatitis in which there was a similar prevalence in all age groups.

As far as the alcohol consumption is concerned, we evaluated the number of patients who regularly drank alcohol and the number of drinks consumed every day (Table 2). Overall, more than $40 \%$ of our patients had at least 1 or 2 drinks/day and $22.7 \%$ had more than 3-4 drinks/day (37.5-50 grams) which is considered to be an unsafe quantity worldwide and in our country. ${ }^{23}$ It is remarkable that we found the same pattern of alcohol consumption in both HBV and HCV hepatitis patients with about 20 to $25 \%$ of viremic patients that had more than 5 drinks/day and consequently could be considered heavy drinkers.
Lastly, 64 out of 631 (10.1\%) patients were diagnosed with NAFLD, $95 \%$ of them had hypertransaminasemia, yet no one had cirrhosis and/or hepatocellular carcinoma (HCC). The age distribution in this etiology was not different in the various age groups (Figure 3).

\section{Discussion and Conclusions}

This study offers new data on the etiology of chronic liver disease in the Southern part of Italy, and particularly in the Campania region, which has the highest mortality rate for liver cirrhosis in Italy. ${ }^{24}$ This data confirms that HCV-related liver diseases still remain the most common etiology and the main cause

Table 2. Daily alcohol consumption in the various etiologies.

\begin{tabular}{|c|c|c|c|c|c|c|c|}
\hline & \multirow[b]{2}{*}{ N (\%) } & \multirow[b]{2}{*}{ Age $(\mathrm{M} \pm \mathrm{SD})$} & \multirow[b]{2}{*}{$\mathbf{M} / \mathbf{F}$} & \multicolumn{4}{|c|}{ Total grams per day } \\
\hline & & & & $12.5-25$ & $37.5-50$ & $62.5-75$ & $>75$ \\
\hline Overall & $\begin{array}{c}277 / 631 \\
(43.89 \%)\end{array}$ & $\begin{array}{c}49.98 \\
( \pm 14.63)\end{array}$ & $206 / 71$ & $\begin{array}{c}134 \\
(48.37 \%)\end{array}$ & $\begin{array}{c}63 \\
(22.74 \%)\end{array}$ & $\begin{array}{c}22 \\
(8.27 \%)\end{array}$ & $\begin{array}{c}58 \\
(22.44 \%)\end{array}$ \\
\hline Only alcohol & $\begin{array}{c}73 / 73 \\
(100 \%)\end{array}$ & $\begin{array}{c}47.44 \\
( \pm 13.57)\end{array}$ & $51 / 22$ & $\begin{array}{c}25 \\
(35.60 \%)\end{array}$ & $\begin{array}{c}18 \\
(24.65 \%)\end{array}$ & $\begin{array}{c}8 \\
(10.95 \%)\end{array}$ & $\begin{array}{c}22 \\
(30.13 \%)\end{array}$ \\
\hline $\mathrm{HCV}$ & $\begin{array}{c}153 / 389 \\
(39.33 \%)\end{array}$ & $\begin{array}{c}55.49 \\
( \pm 15.07)\end{array}$ & $120 / 33$ & $\begin{array}{c}79 \\
(51.63 \%)\end{array}$ & $\begin{array}{c}33 \\
(21.56 \%)\end{array}$ & $\begin{array}{c}11 \\
(7.19 \%)\end{array}$ & $\begin{array}{c}30 \\
(19.6 \%)\end{array}$ \\
\hline $\mathrm{HBV}$ & $\begin{array}{c}32 / 67 \\
(47.76 \%)\end{array}$ & $\begin{array}{c}51.06 \\
( \pm 12.25)\end{array}$ & $25 / 7$ & $\begin{array}{c}16 \\
(50.00 \%)\end{array}$ & $\begin{array}{c}9 \\
(0.28 \%)\end{array}$ & $\begin{array}{c}1 \\
(3.12 \%)\end{array}$ & $\begin{array}{c}6 \\
(18.75 \%)\end{array}$ \\
\hline NAFLD & $\begin{array}{c}5 / 64 \\
(7.81 \%)\end{array}$ & $\begin{array}{c}48.78 \\
( \pm 13.54)\end{array}$ & $4 / 1$ & $\begin{array}{c}5 \\
(100 \%)\end{array}$ & 0 & 0 & 0 \\
\hline Other* & $\begin{array}{c}14 / 14 \\
(100 \%)\end{array}$ & $\begin{array}{c}38.44 \\
( \pm 16.65)\end{array}$ & $6 / 8$ & $\begin{array}{c}9 \\
(64.28 \%)\end{array}$ & $\begin{array}{c}3 \\
(21.42 \%)\end{array}$ & $\begin{array}{c}2 \\
(14.28 \%)\end{array}$ & 0 \\
\hline
\end{tabular}

$\mathrm{M} / \mathrm{F}$, male/female; SD, standard deviation; HCV, hepatitis $\mathrm{C}$ virus; $\mathrm{HBV}$, hepatitis B virus; NAFLD, non-alcoholic fatty liver disease. *Other includes primary biliary cirrhosis, Wilson disease's, drug induced liver disease, and celiac disease.

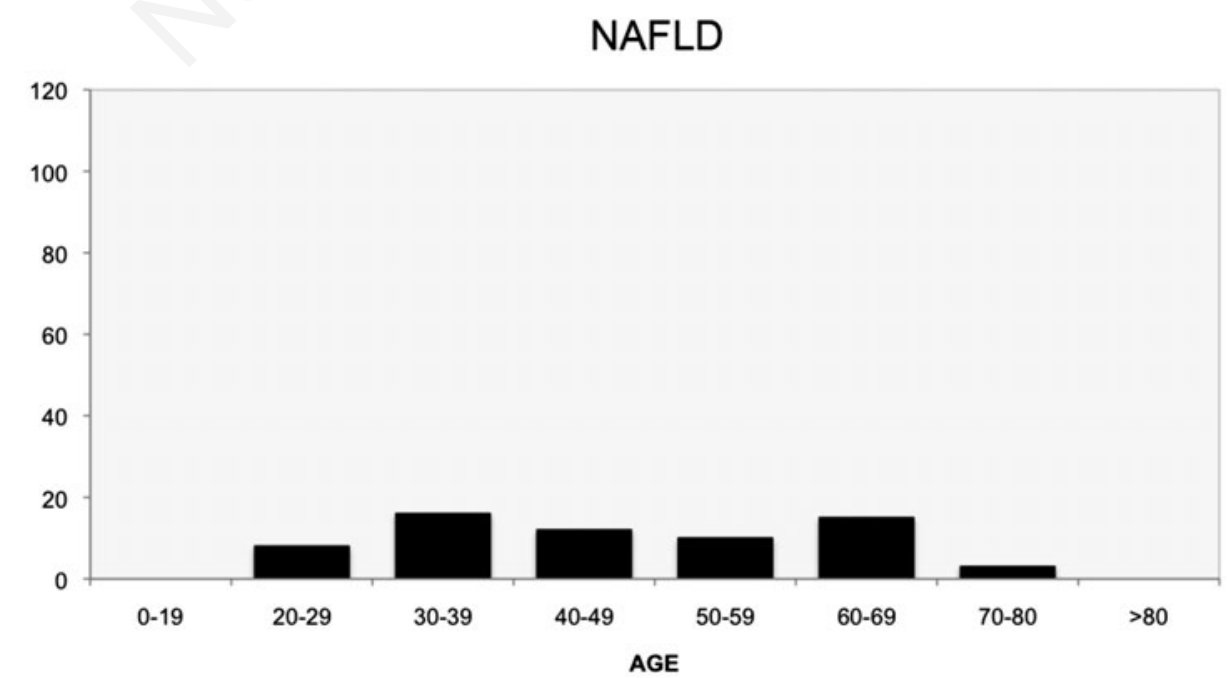

Figure 3. Age distribution of non-alcoholic fatty liver disease (NAFLD) patients. 
for referral to liver centers. Previous studies conducted in the same area showed similar data, ${ }^{13}$ although they reported a slight drop in newly-diagnosed HCV infections in young people. However the data produced by this study does not confirm this finding. In fact $9 \%$ of new cases of HCV chronic infection were in under 30s and $20 \%$ in under 40 s. Presumably HCV infection, after a period of slight decrease, still plays an important role also in young people. Moreover it remains the most common cause of liver disease in middle age, in which $35 \%$ of patients were HCV infected.

Regarding HBV infection, the most interesting finding of this study is that this etiology, even if it is declining, has not disappeared as a cause for referral to hepatologists and it remains the second most common cause of newly-diagnosed liver diseases in our region. It may be argued that this could be related to the presence of inactive carriers that accidentally discover their HBsAg positivity at screening. Even if this hypothesis could explain the higher number of patients with normal ALT at the time of diagnosis, in HBV patients (Figure 1) with respect to all the others, this does not entirely explain this finding. In fact, about 8 out of $75(11 \%)$ HBV patients were in the 20-29 age group, in which, in theory, the compulsory vaccination program should have at least significantly reduced the HBV infection. Moreover, the flat outline of the age prevalence curve of this infection could reflect a change in risk factors of HBV infection. Many years ago the most important cause of infection was vertical transmission, now it is sexual transmission, tattooing, piercing and intravenous drug abuse, which are more frequent among young people.

Alcoholic liver disease represents a social problem also in our region, involving young people as well. In this study, about $12 \%$ of patients had an alcoholic liver disease with a flat age group distribution. Only $4.6 \%$ of these patients were under 30 years of age, but this prevalence rises to $25 \%$, if we also consider patients under 39 years, suggesting that alcoholic liver disease takes time to be diagnosed or, eventually, to cause a quantifiable liver damage. However, about $40 \%$ of $\mathrm{HBV}$ and $\mathrm{HCV}$ patients had at least 1 alcoholic drink daily, and, of these, almost $20 \%$ had more than 5 drinks per day, which is defined as an unsafe quantity. ${ }^{25}$ The synergistic effect that alcohol (in any amount) has on liver damage in any liver diseases is well-known. In fact a good clinical management of liver patients should include an accurate counseling on alcohol consumption. It must be noted that our patients consumed that amount of alcohol, being unaware of having a liver disease. This group of patients (20\%) should be considered affected by a double etiology: viruses and alcohol. This prevalence is very high in respect to what was found in another recent multicentric study, in which a double etiology (HCV+alcohol) was identified in about $11 \%$ of patients. ${ }^{13}$ Moreover, alcohol consumption of any amount was associated with an increased risk of cirrhosis and/or HCC in HCV and HBV positive patients (relative risk: $2.22 ; 95 \%$ confidence interval: 1.35-3.66). This data confirms the findings of another recent study on a large cohort of HCV patients that consumed alcohol in spite of their liver disease. ${ }^{13}$

Lastly, the prevalence of patients with newly-diagnosed NAFLD is about $10 \%$ in our population. This data confirms that this is an emerging issue in liver patients. The age distribution pattern was flat like for alcoholic liver disease. It must be noted that $5 \%$ of these patients had ALT at the upper normal limit and, consequently, some liver damage. These patients were presumably suffering from a liver disease, despite a simple lipid accumulation in the liver; nevertheless no one had cirrhosis and/or HCC. This particular presentation may be due to the NAFLD diagnostic criteria themselves, in which there has to be hypertransaminasemia together with bright liver on ultrasonography and/or steatosis in liver biopsy with no other cause of liver disease. Therefore every steatosis without ALT elevation was excluded. It is also well-known that progression to cirrhosis in NASH is accompanied by the disappearance of lipid accumulation in the liver accounting for the erroneous diagnosis of cryptogenic cirrhosis often made in this group of patients. This issue may explain the total absence of cirrhosis and/or $\mathrm{HCC}$, but also confirm the general idea of NAFLD as a mild disease which only occasionally might progress to end-stage liver disease.

In conclusion, this study confirms that $\mathrm{HCV}$ chronic infection is still the most important cause of liver disease in Southern Italy. Despite previous indications, it continues to involve also young people. HBV infection is still relevant as a newly-diagnosed liver disease etiology and it continues to spread among young people, despite the vaccination program. NAFLD is an emerging issue also in our region.

\section{References}

1. Spada E, Mele A, Ciccozzi M, et al. T. SEIEVA collaborating group. Changing epidemiology of parenterally transmitted viral hepatitis: results from the hepatitis surveillance system in Italy. Dig Liver Dis 2001;33:778-84.

2. Giusti G, Sagnelli E, Gallo CC, et al. The etiology of chronic hepatitis in Italy: a multicenter study. Hepatogastroenterology 1994;41:397-400.

3. Gaeta GB, Stornaiuolo G, Precone et al. Epidemiological and clinical burden of chronic hepatitis B virus/hepatitis $\mathrm{C}$ virus infection. A multicenter Italian study. J Hepatol 2003;39:1036-41.

4. Bellentani S, Tiribelli C, Saccoccio G, et al. The prevalence of chronic liver disease in general population of 
Northern Italy: the Dionysos study. Hepatology 1994; 20:1442-9.

5. Bellentani S, Tiribelli C. The spectrum of liver disease in the general population; lesson from the Dionysos study. J Hepatol 2001;35:531-7.

6. Pendino GM, Mariano A, Surace P, et al. Prevalence and etiology of altered liver tests: a population-based survey in a Mediterranean town. Hepatology 2005;41:1151-9.

7. Stroffolini T, Sagnelli E, Almasio P, et al. Characteristics of liver cirrhosis in Italy: results from a multicenter national study. Dig Liver Dis 2004;36:56-60.

8. Stroffolini T, Chiaramonte M, Craxì A, et al. Baseline sero-epidemiology of hepatitis B virus infection in children and teenagers in Italy. A survey before mass hepatitis B vaccination. J Infect 1991;22:191-9.

9. Stroffolini T. The changing pattern of hepatitis B virus infection over the past three decades in Italy. Dig Liver Dis 2005;37:622-7.

10. Guadagnino V, Stroffolini T, Rapicetta M, et al. Prevalence, risk factors and genotype distribution of Hepatitis $\mathrm{C}$ virus infection in the general population: a community based survey in Southern Italy. Hepatology 1997;26: 106-11.

11. Bellentani S, Pozzato G, Saccoccio G, et al. Clinical course and risk factors of hepatitis $\mathrm{C}$ virus related liver disease in the general population: report from the Dionysos study. Gut 1999;44:874-80.

12. Maio G, d'Argenio P, Stroffolini T, et al. Hepatitis C virus infection and alanine transaminase levels in the general population: a survey in a southern Italian town. J Hepatol 2000;33:116-20.

13. Sagnelli E, Stroffolini T, Mele A, et al. The importance of $\mathrm{HCV}$ on the burden of chronic liver disease in Italy: a multicenter prevalence study of 9,997 cases. J Med Virol 2005;75:522-7.

14. Stroffolini T, Sagnelli E, Mariano A, et al. Characteristics of HCV positive subjects referring to hospitals in Italy: a multicentre prevalence study on 6,999 cases. J Viral Hepat 2006;13:351-4.
15. Romanò L, Azara A, Chiaramonte M, et al. Low prevalence of anti-HCV antibody among Italian children. Infection 1994;22:350-52.

16. Bellentani S, Bedogni G, Miglioli L, Tiribelli C. The epidemiology of fatty liver. Eur J Gastroenterol Hepatol 2004; 16:1087-94.

17. Browning JD, Szczepaniak LS, Dobbins R, et al. Prevalence of hepatic steatosis in an urban population in the United States: impact of ethnicity. Hepatology 2004;40: 1387-95.

18. Bedogni G, Miglioli L, Masutti F, et al. Prevalence and risk factors for non alcoholic fatty liver disease: the Dyonisos nutrition and liver study. Hepatology 2005; 42:44-53.

19. Williams R. The pervading influence of alcoholic liver disease in hepatology. Alcohol Alcohol 2008;43:393-7. PMID: 18385413

20. Aricò S, Corrao G, D'Amicis A, et al. Alcoholic liver cirrhosis after the advent of Hepatitis $\mathrm{C}$ virus: some reflections on its epidemiology and on the concept of attributable risk. Ital J Gastroenterol Hepatol 1997;29: 75-80.

21. Lonardo A, Bellini M, Tartoni P, Tondelli E. The bright liver syndrome. Prevalence and determinants of a "bright" liver echopattern. Ital J Gastroenterol Hepatol 1997;29:351-6.

22. Palmentieri B, de Sio I, La Mura V, et al. The role of bright liver echo pattern on ultrasound B-mode examination in the diagnosis of liver steatosis. Dig Liver Dis 2006;38:485-89.

23. Corrao G, Aricò S, Ascione A. Epidemiology of chronic liver disease in Italy. Ital J Gastroenterol 1994;26:44-9.

24. De Luca M, Di Costanzo GG, Picciotto FP, et al. Mortality for liver cirrhosis in Italy. Dig Liv Dis 2005; 37;A42.

25. Loguercio C, Federico A, Masarone M, et al. The impact of diet on liver fibrosis and on response to interferon therapy in patients with HCV-related chronic hepatitis. Am J Gastroenterol 2008;103:3159-66.

\section{APPENDIX The SCIROCCO Study Group}

Antonio Ascione (Napoli), Mario Masarone (Napoli), Giovanni Tritto (Napoli), Carmine Coppola (Castellammare di Stabia, NA), Cristina Mascolo (Castellammare di Stabia, NA), Marcello Persico (Napoli), Giovanbattista Forte (Caserta), Luca Fontanella (Napoli), Massimo De Luca (Napoli), Giovan Giuseppe Di Costanzo (Napoli), Guido Piai (Caserta), Roberto Torella (Napoli), Antonio Salvio (Napoli), Perla Minicone (Napoli), Alfonso Vitagliano (Napoli), Giovanni Massimiliano Claar (Aversa, NA), Alba Rocco (Napoli), Giuseppe Maio (Benevento), Alessandro Federico (Napoli), Carmela Loguercio (Napoli), Nicola Caporaso (Napoli), Filomena Morisco (Napoli), Giuseppe D'Adamo (Nocera Inferiore, NA), Ubaldo Baldi (Nocera Inferiore, NA), Salvatore D'Angelo (Avellino), Pasquale Esposito (Napoli), Crescenzo Izzo (Napoli), Ernesto Claar (Aversa, NA), Felice Piccinino (Napoli), Herbert Ferretti (Napoli), Giampiero Francica (Casoria, NA), Andrea Fontanella (Napoli). 